[Agr. Biol. Chem., Vol. 30, No. 7, p. 688 692, 1966]

\title{
Studies on the Decomposition of Sinalbin
}

\section{Part I. The Decomposition Products of Sinalbin}

\author{
By Shunro Kawakishi ${ }^{*}$ and Keiichiro Muramatsu \\ Department of Agricultural Chemistry, Faculty of Agriculture, \\ Shizuoka University, Iwata, Shizuoka-ken
}

Received February 8, 1966

\begin{abstract}
In the mustard paste, sinalbin is hydrolyzed by myrosinase to $p$-hydroxybenzyl isothiocyanate (I), sinapine acid sulfate and glucose. It was found that the three decomposition products were formed from sinalbin, and two of them were isolated from the mustard paste and identified as $p$-hydroxybenzyl alcohol (II) and di-( $p$-hydroxybenzyl)disulfide (IV), respectively. II was a major product and IV was a minor product.
\end{abstract}

Sinalbin, the mustard oil glucoside in seeds of white mustard (Sinapis alba L.), is decomposed by myrosinase to $p$-hydroxybenzyl isothiocyanate $(\mathrm{I})$, sinapine acid sulfate and glucose. We observed that I was disapperared from the mustard paste in several hours ${ }^{11}$ The loss of its characteristic pungent taste was attributed to the secondary decomposition of I. R. Gmelin and A. I. Virtanen ${ }^{21}$ demonstrated the presence of thiocyanate ion $\left(\mathrm{SCN}^{-}\right)$ in the crushed and moistend seeds of different Brassica species. They have considered that the precursors of $\mathrm{SCN}^{-}$is mustard oil glucoside, and the mustard oil formed from the glucoside spontaneously is hydrolyzed to alcohol and $\mathrm{SCN}^{-}$In this paper, we would like to report on the formation, isolation and identification of two decomposition products of sinalbin.

The paste of white mustard, prepared from 1 part of mustard powder and 1.5 parts of water, was incubated at $37^{\circ} \mathrm{C}$ and periodically extracted with ether. The extracts were subjected to paper chromatography (Fig. 1).

\footnotetext{
* Present address: Department of Agricultural Chemistry, Faculty of Agriculture, Nagoya University, Nagoya

1) S. Kawakishi, Presented at the Symposium of Chübu Branch, The Agricultural Chemical Society of Japan, Ort. 9, 1965.

2) R. Gmelin and A.I. Virtanen, Acta. Chem. Scand., 14, 507 (1960).
}

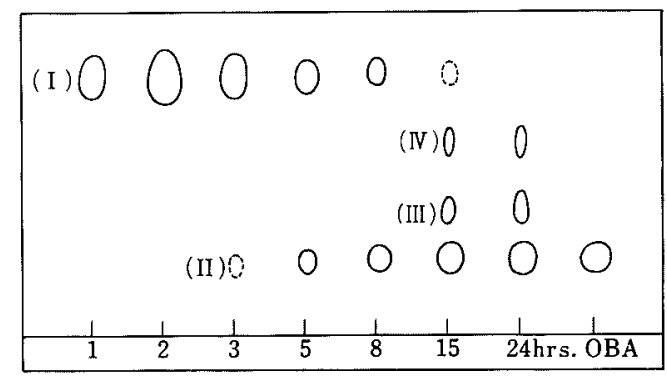

FIG. 1. Paper Chromatogram of Ether Extracts of the Mustard Paste

Samples: Ether extracts of the paste which was incubated at $37^{\circ} \mathrm{C}$ for $1,2,3,5,8,15$ and 24 hrs., respectively. OBA: Authentic $p$-hydroxybenzyl alcohol.

Solvent, Xylene: dimethylformamide (85:15).

Coloring reagent, Diazotized sulfanilic acid and $10 \%$ $\mathrm{Na}_{2} \mathrm{CO}_{3}$ soln.

The results indicated that I was disappeared in fifteen hours and three products (II, III, IV) were newly appeared on the chromatogram. These three products were positive to a diazo reagent and III and IV were also positive to a iodine-azide reagent. These facts suggest that II, III and IV are phenolic compounds and III and IV are sulfur containing compounds. In the reaction mixture of sinalbin and myrosinase ( $\mathrm{pH} \mathrm{5.2),} \mathrm{II,} \mathrm{III} \mathrm{and} \mathrm{IV} \mathrm{were}$ also found as in the case of the mustard paste, but I disappeared faster than that of the paste. 
In both cases, II was a major product, and III and IV were minor products. II was identical with authentic p-hydroxybenzyl alcohol on the chromatogram. III was converted to IV by treatment with dilute alkali without heating (Fig. 2) suggesting the formation of IV through III in the paste.

The formation of $\mathrm{SCN}^{-}$in the mustard paste and the reaction mixture of sinalbin and myrosinase was studied by the colorimetric method of N. Michajlovskij et al. ${ }^{3)}$

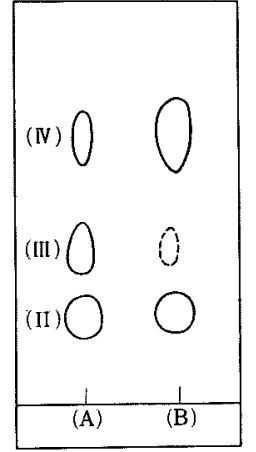

(1)

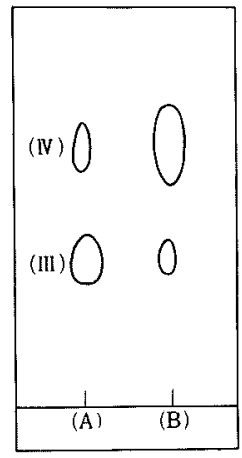

(2)
FIG. 2. Conversion of the Product III to IV. Samples

(A): Ether extract of the mustard paste incubated at $37^{\circ} \mathrm{C}$ for $48 \mathrm{hrs}$

(B): Ether extract of the acidified aqueous solution which was shaken with $5 \% \mathrm{NaOH}$ of sample (A). Solvent, Xylene : dimethylformamide (85:15). Coloring reagent, (1) Diazotized sulfanilic acid and $10 \% \mathrm{Na}_{2} \mathrm{CO}_{3}$ soln. (2) Iodine-azide soln.

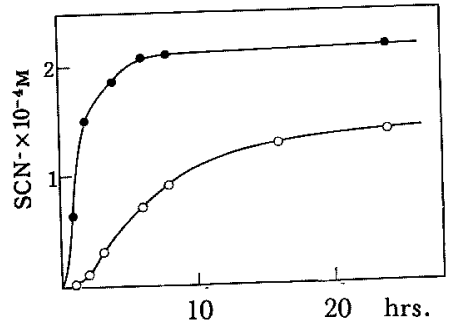

FIG. 3. Formation of SCN- from Sinalbin.

\footnotetext{
- $-\mathrm{O}-$ - The mustard paste.

- The reaction mixture of sinalbin and myrosinase. The values show $\mathrm{SCN}^{-}$mole number per gram of the mustard powder and $100 \mathrm{ml}$ of the reaction mixture.
}

3) N. Michajlovskij und P. Langer, Hoppe Seyler's $Z$. Physiol. Chem., 312, 26 (1958).
$\mathrm{SCN}^{-}$increased with time in both cases, and the increase reached equilibrium in fifteen hours for the paste and in six hours for the reaction mixture, respectively (Fig. 3). These were corresponded with the disappearance of I on the chromatogram.

II and IV were isolated from the paste by the procedures shown in Fig. 4, while attempt. to isolate III was unsuccessful. II was recrystallized from water. M. p. $124 \sim 5^{\circ} \mathrm{C}$. The crystal showed no depression by admixture with authentic p-hyroxybenzyl alcohol. The isolated and authentic samples had identical IR spectra ${ }^{1 /}$ (Fig. 5a). Recently, T. Yamanishi et al. ${ }^{4)}$ reported the isolation of

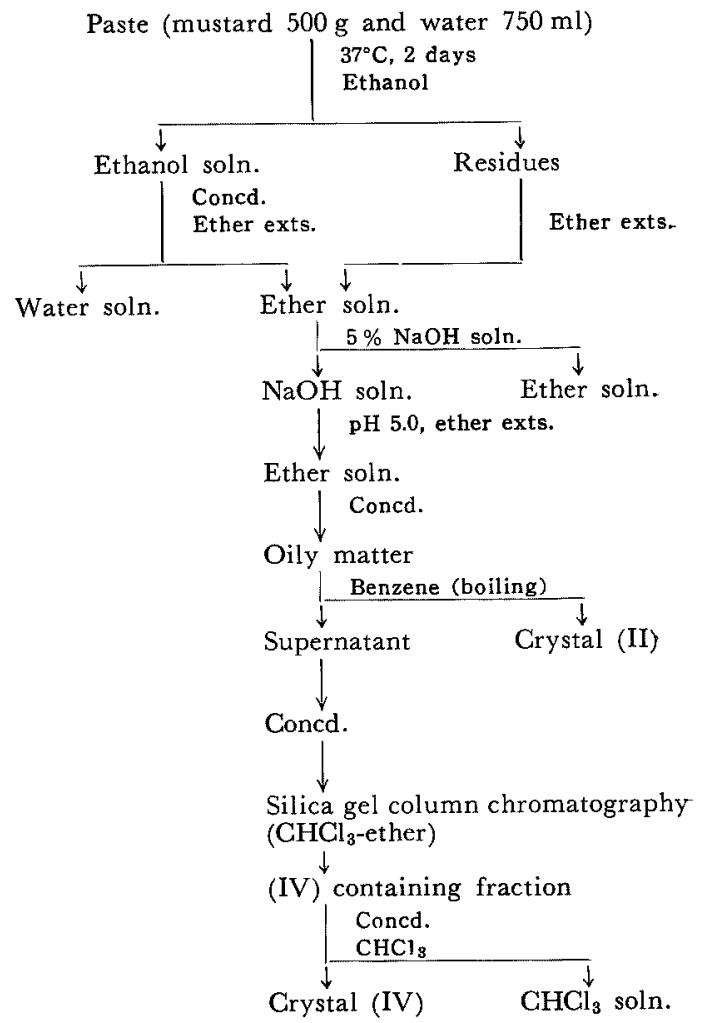

FIG. 4. Isolation Procedures of Decomposition Products from the Mustard Paste

4) T. Yamanishi, A. Kobayashi and S. Oyamada, J. Agr. Chem. Soc. Japan, 39, 454 (1965). 


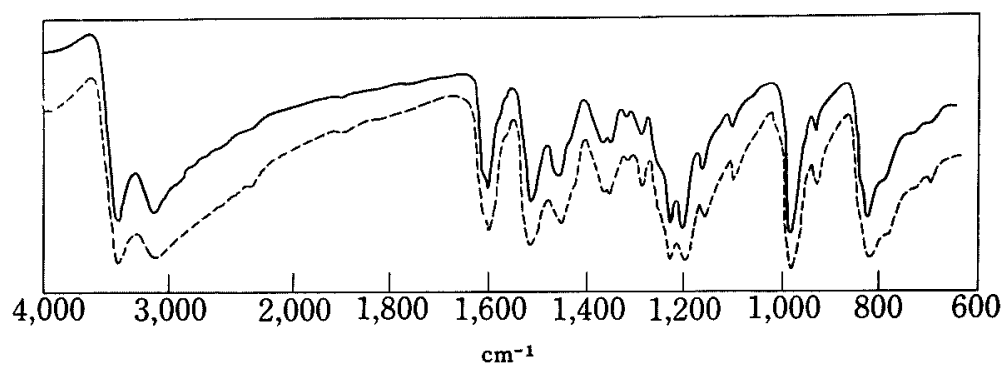

FIG. 5a. IR Spectrum of II.

- isolated, -..... authentic sample.

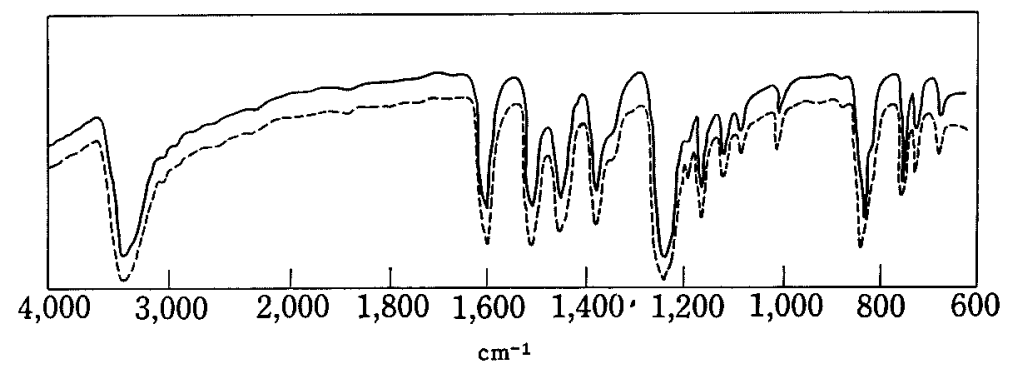

FIG. 5b. IR Spectrum of IV.

- isolated, ...... synthesized sample.

$p$-hydroxybenzyl alcohol from the paste of white mustard. IV was recrystallized from dilute ethanol. M. p. $172^{\circ} \mathrm{C}$. Elementary analyses supported $\mathrm{C}_{14} \mathrm{H}_{14} \mathrm{O}_{2} \mathrm{~S}_{2}$ for its molecular formula. From the UV spectrum $\left(\lambda_{\max } 238\right.$, $280 \mathrm{~m} \mu)$ and the IR spectrum $(3340,1608$, $1600,1510,1240,840 \mathrm{~cm}^{-1}$ ) (Fig. 5b), it was assumed to have $p$-substituted phenol group. The mass spectrum showed the greater peak in $\mathrm{M} / \mathrm{e} 77\left(\mathrm{C}_{6} \mathrm{H}_{5}{ }^{+}\right), 107\left(\mathrm{HOC}_{6} \mathrm{H}_{4} \mathrm{CH}_{2}{ }^{+}\right)$and $140\left(\mathrm{HOC}_{6} \mathrm{H}_{4} \mathrm{CH}_{2} \mathrm{SH}^{+}\right)$. From these facts, its constitution seemed to be $\mathrm{di}$-( $p$-hydroxybenzyl)-disulfide. This compound, m.p. $171^{\circ} \mathrm{C}$ was prepared from $p$-hydroxybenzyl alcohol by a modified method of U. Schmidt et al. ${ }^{5)}$ who synthesized di-(o-hydroxybenzyl)disulfide from o-hydroxybenzyl alcohol. The mixed melting point with IV was not depressed and the IR spectrum was identical

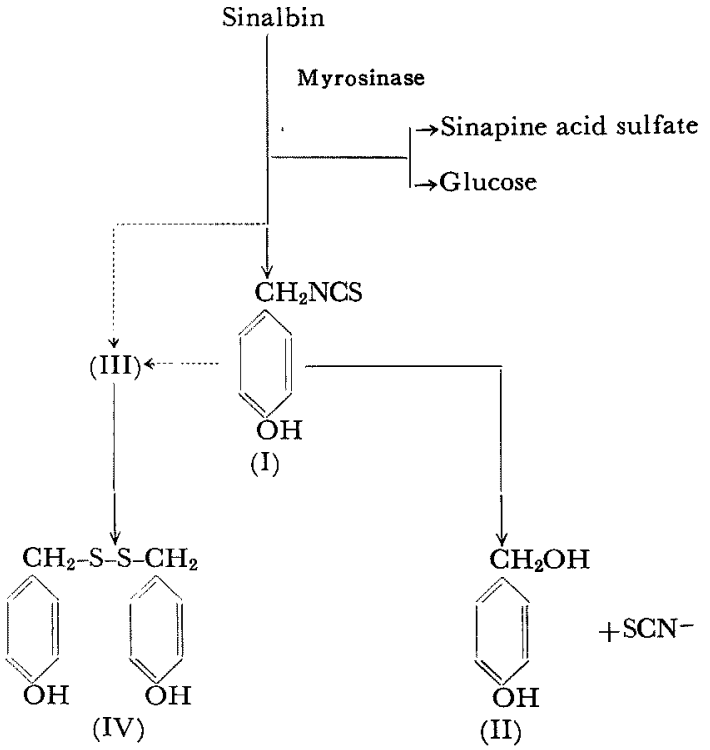

FIG. 6. Scheme of Sinalbin Degradation

5) U. Schmidt und G. Giesselmann, Ann., 657, 162 (1962). 
with that of IV (Fig. 5b).

The degradation scheme of sinalbin is shown in Fig. 6. The quantitative determination of $\mathrm{SCN}^{-}$in the reaction mixture of sinalbin and myrosinase suggested that nearly $90 \%$ of added sinalbin was decomposed as follows:

Sinalbin $\underset{\text { myrosinase }}{\rightarrow} p$-Hydroxybenzyl isothiocyanate (I)

$\underset{\mathrm{SCN}^{-}}{\longrightarrow}$-Hydroxybenzyl alcohol (II) +

It is clear, by paper chromatography that IV was formed from sinalbin. However, it is unknown whether IV was directly formed from I or not. It is interesting that the disulfide derivative was formed from mustard oil glucoside under physiological conditions.

\section{EXPERIMENTAL}

Preparation of Sinalbin from Mustard Powder. Mustard powder $(300 \mathrm{~g})$ were defatted by petroleum benzine, and then extracted three times with 11 of $90 \%$ ethanol in reflux conditions. The ethanol solution was concentrated under reduced pressure. Sinalbin obtained from the concentrated solution was recrystallized from $80 \%$ ethanol. Yield, $8 \mathrm{~g}$. M.p. $82 \sim 3^{\circ} \mathrm{G}$.

Preparation of Myrosinase. Myrosinase was prepared from mustard powder by the procedure of $Z$. Nagashima et al,6) The suspension prepared from $100 \mathrm{~g}$ of the mustard powder and $300 \mathrm{ml}$ of water was allowed to stand for two hours at room temperature and then centrifuged. Equal volume of $80 \%$ ethanol was added to the suppernatant, and the precipitate was removed by centrifugation. To this suppernatant, 2.5 volumes of $90 \%$ ethanol were added, and the precipitate was collected by centrifugation, washed with ethanol and ether successively, and dried under reduced pressure. This powder was used as myrosinase preparation.

Paper Chromatography of the Decomposition Products

1) The Mustard Paste. The pastes, prepared from $20 \mathrm{~g}$ of mustard powder and $30 \mathrm{ml}$ of water for each part, were incubated at $37^{\circ} \mathrm{C}$ and extracted with ether after 1, 2, 3, 5, 8, 15 and $24 \mathrm{hrs.,}$, respectively.

\footnotetext{
6) Z. Nagashima and M. Uchiyama, J. Agr. Chem. Soc. Japan, 33, 478 (1960).
}

The ether extracts were dried with anhydrous sodium sulfate and concentrated. The components in the extracts were examined by paper chromatography using xylene-dimethylformamide (85:15, v/v). Each component was detected with diazotized sulfanilic acid-sodium carbonate solution (Fig. 1) and iodineazide solution.?

2) The Reaction Mixture of Sinalbin and Myrosinase. The reaction mixture was consisted of $20 \mathrm{ml}$ of $0.2 \mathrm{mM}$ sinalbin, $40 \mathrm{ml}$ of $0.1 \mathrm{M}$ acetate buffer ( $\mathrm{pH} \mathrm{5.2)}$ and $40 \mathrm{ml}$ of enzyme solution. This was incubated at $37^{\circ} \mathrm{C}$ and extracted with ether after I, 2, 3, 5 and 8 hrs., respectively. Each extract was subjected to paper chromatography by the identical method for the paste.

3) Conversion of the Product III to IV. The paste was incubated at $37^{\circ} \mathrm{C}$ for $48 \mathrm{hrs}$. and extracted with ether. Half part of the ether extract was dried and concentrated (A). Another half was shaken with $5 \% \mathrm{NaOH}$ and the aqueous solution was acidified to pH 5.0 with $2 \mathrm{~N}_{2} \mathrm{H}_{2} \mathrm{SO}_{4}$ and extracted with ether (B). The samples A and $B$ were examined by paper chromatography (Fig. 2).

Determination of SCN- formed from Sinalbin. $\mathrm{SCN}^{-}$was determined by the colorimetric method of $\mathrm{N}$ Michajlovskij et al.3) Five milliliters of sample solution was mixed with $1 \mathrm{ml}$ of $\mathrm{Fe}$ reagent $(5.0 \mathrm{~g}$ of ferric nitrate, $2.5 \mathrm{ml}$ of conc. nitric acid and made up to $100 \mathrm{ml}$ with water), measured at $500 \mathrm{~m} \mu$ with a colorimeter, and the values were compared with a standard $\mathrm{SCN}^{-}$curve.

Isolation and Identification of the Decomposition Products II and IV

1) Isolation of the Products. The isolation procedures of II and IV from the paste of white mustard are illustrated in Fig. 4. Yields of II and IV from $500 \mathrm{~g}$ of mustard powder were $0.6 \mathrm{~g}$ and $0.06 \mathrm{~g}$, respectively. In this process, it was considered that the product III was converted to IV by alkali treatment.

2) Identification of the Products. II was recrystallized from water. M.p. $124 \sim 5^{\circ} \mathrm{C}$. The mixed m.p. with authentic $p$-hydroxybenzyl alcohol, $121^{\circ} \mathrm{C}$. The isolated and authentic samples had identical IR spectra (Fig. 5a). IV was recrystallized from dilute ethanol. M. p. $172^{\circ}$ C. M.w. 280 (by Rast method). Anal. Found: C, 60.25; H, 4.80; S, 21.75.

\footnotetext{
7) F. Feigl, "Spot Tests in Organic Analysis". Elsevier p. 228,1956 .
} 
Calcd. for $\mathrm{C}_{14} \mathrm{H}_{14} \mathrm{O}_{2} \mathrm{~S}_{2}: \mathrm{C}, 60.43 ; \mathrm{H}, 5.03 ; \mathrm{S}, 23.02 \%$. The UV spectrum in ethanol showed $\lambda_{\max } 238$ and $280 \mathrm{~m} \mu(\log \varepsilon 4.32$ and 3.52$)$, and the IR spectrum is shown in Fig. $5 \mathrm{~b}$.

3) Synthesis of Di-( $p$-Hydroxybenzyl)-Disulfide. Six grams of $p$-hydroxybenzyl alcohol and $9 \mathrm{ml}$ of carbon disulfide were shaken with $3.5 \mathrm{~g}$ of sodium in $75 \mathrm{ml}$ ethanol during two days. After concentration, water was added to the residue, and the solution was acidified with acetic acid and extracted with benzene. The benzene extract was concentrated and the oily matter was removed with chloroform from the residue. The residue was crystallized in refrigerator and recrystallized from dilute ethanol. Yield $0.4 \mathrm{~g}$. M.p. $171^{\circ} \mathrm{C}$. The mixed m.p. with the product IV, $172^{\circ}$ C. Anal. Found: C, 60.13; H, 4.89; S, 22.83 . Calcd. for $\mathrm{C}_{14} \mathrm{H}_{14} \mathrm{O}_{2} \mathrm{~S}_{2}: \mathrm{C}, 60.43 ; \mathrm{H}, 5.03 ; \mathrm{S}, 23.02 \%$.

Acknowledgement. We wish to express our thanks to Prof. K. Munakata, Prof. M. Namiki and Dr. H. Aoki, the Nagoya University for helpful guidance, and to Department of Agricultural Chemistry, the Nagoya University and the Institute of Physical \& Chemical Research for elementary analyses. 